\title{
Surgery for sight: outcomes of congenital and developmental cataracts operated in Durban, South Africa
}

${ }^{1}$ Orbis Africa, Cape Town, Republic of South Africa

${ }^{2}$ African Vision Research Institute, University of KwaZulu Natal, Durban, Republic of South Africa

${ }^{3}$ Dr Gogate's Eye Clinic, Pune, India

${ }^{4}$ Department of Ophthalmology, Inkosi Albert Luthuli, Central Hospital, Durban, KwaZulu Natal, Republic of South Africa

${ }^{5}$ Brien Holden Vision Research Institute, Durban, Republic of South Africa

${ }^{6}$ School of African and Gender Studies, Anthropology and Linguistics, University of Cape Town, Cape Town Republic of South Africa

${ }^{7}$ Consultant Ophthalmic Surgeon, Stoke Mandeville Hospital, Aylesbury, Bucks, UK

Correspondence: P Gogate, Dr Gogate's Eye Clinic, 102, Kumar Garima, Tadiwala Road, Pune 411 001, India Tel: +91202605 9723. E-mail: parikshitgogate@ hotmail.com

Received: 9 December 2014 Accepted in revised form: 27 August 2015

Published online:

27 November 2015

\begin{abstract}
Purpose To study the visual outcomes of congenital and developmental cataract surgery and determine variables for presentation for pediatric cataract surgery in KwaZulu Natal province of South Africa. Methods Care-givers of children presenting with cataract to a quaternary centre were asked when they first detected the condition. The reasons for delay between detection and surgery were studied. The children underwent a comprehensive eye examination and then appropriate surgery. They were prospectively followed up for 3 months and visual acuity and stereopsis were noted. Delay in presentation for surgery and visual outcomes were co-related with demographic and clinical factors. Results Eighty-three non-traumatic cataract surgeries in $\mathbf{5 0}$ children were studied. Twenty-six (52\%) were males, mean age was 3 years 10 months (SD 3yrs 4 months). The mean delay between identification and surgery was 20.7 months (SD 18 months). Twenty-six (52\%) children had >15 months interval between diagnosis and surgery. Only mother's occupation was significantly associated with delay $(P=0.017)$. Post-surgery $17 / 69(24.7 \%)$ had visual acuity $\geq 6 / 18,20 / 69$ $(29.0 \%)$ had vision between $6 / 24-6 / 60$, whereas $32 / 69(46.3 \%)$ had visual acuity $\leq 6 / 60$. The final vision was associated with age $(P=0.031)$, delay between diagnosis and surgery $(P<0.001)$, type of surgery $(P=0.046)$ and preoperative vision $(P<0.001)$. Conclusion Although the children's vision improved substantially, a longer follow-up and amblyopia treatment would be necessary to optimize the visual outcome, which depended on age and preoperative vision. Health promotion activities aimed at mothers are important in improving visual outcomes.
\end{abstract}

P Gogate ${ }^{1,2,3}$, D Parbhoo ${ }^{4}$, P Ramson', R Budhoo ${ }^{4}$, L Øverland', N Mkhize', K Naidoo ${ }^{2,5}$,

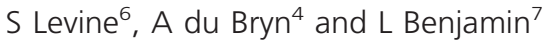

Eye (2016) 30, 406-412; doi:10.1038/eye.2015.211; published online 27 November 2015

\section{Introduction}

Pediatric cataracts are one of the few treatable causes of blindness in children. ${ }^{1}$ Blindness in children places enormous burden on their families as these children have a lifetime of blindness ahead of them. In terms of blind-person years, childhood blindness is one of the leading causes of blindness burden globally. ${ }^{2}$ As Vitamin A supplementation and vaccination coverage have improved, corneal cause of childhood blindness has declined and the proportion of cataract induced blindness in children has increased. ${ }^{3}$ Cataract in children differs from adults in that there are chances of amblyopia development if it is not addressed within a specified period and the eye is anatomically different as the anterior capsule is more elastic, the sclera less rigid and the chances of posterior capsular opacification nearly $100 \% .4,5$ The technique of cataract surgery in children also differs as it does not involve only cataract removal with intraocular lens (IOL) implantation, but also primary posterior capsulotomy and anterior vitrectomy followed by suturing of the incision and side ports at the end. ${ }^{6}$

Whereas there have been numerous reports of outcomes of cataract surgery from developed countries like the USA and UK and developing countries like India, China and Nepal, there have been few reports from Africa which houses the largest population of children with cataract after Asia. ${ }^{7-13}$ Studies from Kenya investigated early outcomes, whereas others from Tanzania focused on bilateral pediatric cataracts. ${ }^{14-16}$ There have been no reports of pediatric cataract outcomes from the Republic of South Africa, 
which has perhaps the most advanced system of health care in sub-Saharan Africa.

This study presents the 3 month visual outcomes of congenital and developmental cataracts operated in Durban, South Africa and the demographic and clinical factors influencing outcome. It also aimed to find if there was any delay between detection of the cataract and its treatment by surgery, and the factors associated with such a delay.

\section{Materials and methods}

The study was conducted between June 2012 and June 2014 in the pediatric ophthalmology clinic of a quaternary public hospital. The surgeries were done between April 2013 and February 2014. It was a prospective, longitudinal, hospital-based interventional study. Permission was sought for and obtained from the ethical committees of the University of KwaZulu-Natal, Provincial Department of Health and Inkosi Albert Luthuli Central Hospital, Durban. The children had undergone cataract surgery with IOL implantation, the power of which had been calculated using Dahan's formula and then underestimated depending on age. ${ }^{17}$ The categorization developmental or congenital was based on morphology and history. Any cataract noticed in the first 6 months of life was categorized as congenital. Cataracts in which the zonular involvement was clearly seen and with 'riders' were classified as developmental. Two surgeons implanted the IOL in the bag for children 4 months of age and older. IOLs were not implanted if the corneal diameter was $<9.5 \mathrm{~mm}$. Primary posterior capsulotomy (PPC) and anterior vitrectomy (AV) was performed till 6 years of age. Hydrophobic acrylic IOLs were used for children over 4 months of age. They were prescribed topical steroid-antibiotic drops for 6 weeks in tapering doses along with cycloplegic eye drops for the first 2 weeks. Amblyopia treatment and spectacle correction had been prescribed at the 1-week follow-up. The children were to have 6 week, 3 month, 6 month and then at least an annual follow-up.

Children identified with cataracts in primary healthcare centres or pediatric clinics were referred to the quaternary hospital for treatment as per South African health-care system. Demographic data were recorded. The children underwent a comprehensive ocular examination comprising a slit-lamp examination, orthoptic evaluation, tonometry, fundoscopy, and cycloplegic refraction. Visual acuity was measured by the Preferential looking chart, crowded Kay, Lea symbols or Snellen's chart depending on the age and co-operation of the child, intraocular pressure (IOP) by an I-care tonometer and stereoacuity with Titmus fly test. All the children underwent phacoaspiration with Alcon constellation machine. The wound and side-port were sutured with 10-0 vicryl. The parents and children were also counselled during this visit about the importance of follow-up on discharge. The addresses and telephonic details of each caregiver was recorded to allow for reminders of subsequent follow-up visits.

If a child had $>15$ months lag between identification of cataract and surgery, then it was termed 'delay'. This cutoff was taken from published literature of other African and Asian studies. ${ }^{18}$ A delay of up to 1 year was deemed common and only those who had a longer interval between detection of cataract and its surgery were termed as 'delayed presenters for surgery'. Statistical analysis was conducted using the SPSS version 19 software (IBM Corporation, Bangalore, India) including multivariate analysis with binary logistic regression. Qualitative investigations involved interviews, using semistructured questionnaires with care givers to determine barriers to presenting for cataract surgery.

\section{Results}

Fifty children with congenital and developmental cataracts operated and followed-up for 3 months were included in the study. In all, 24/50 (48\%) were females and 49/50 children were of black ethnicity The cataract was detected at an average age of 2 years 2 months. Their ages ranged from 10 days to 12 years at the time of surgery (mean 3 years 10 months, SD 3 year 4 months). Six out of $83(7.2 \%)$ cataractous eyes had been operated at $<6$ months of age, 18/83 (21.7\%) between 7-12 months, $8 / 83(9.6 \%)$ between $13-24$ months, $27 / 83$ (32.5\%) at the age of $25-60$ months and $24 / 83(28.9 \%)$ at $>60$ months of age. Nine eyes had microphthalmos and four had retinopathy. One eye had congenital glaucoma in addition to cataract.

There was an average 20.7 month (SD 18 months) delay between the identification and surgical treatment of the cataract. Twenty-six children had a delay of $>15$ months between identification and surgical treatment of cataracts. Visual acuity of 69 eyes was available at the 3 months follow-up.

The commonest barriers to accessing cataract surgical service were: did not feel the need $7 / 26$ (26.9\%), we thought the child was seeing fine $7(26.9 \%)$, health centre or GP told us the child was okay or the child was undergoing treatment at another hospital 4 (15.4\%). Two respondents each stated: did not notice it, had shown to a traditional healer, nobody told us the condition could be cured and could not afford to travel. There was no 'delay' in $24 / 50(48 \%)$ of the children. The causes of delay are enumerated in Table 1.

Table 2 shows the various demographic and clinical factors associated with delay in presentation for surgery. 
Table 1 Causes of delay in presentation for surgery to the hospital

\begin{tabular}{ll}
\hline No delay & $24 / 50(48 \%)$ \\
Causes for delay in presentation & $\mathrm{n}(\%)$ \\
Child was seeing fine & $7(26.9 \%)$ \\
Did not feel the need & $7(26.9 \%)$ \\
Did not notice the cataract & $2(7.7 \%)$ \\
Visited traditional healer & $2(7.7 \%)$ \\
Cannot afford to travel to the hospital & $2(7.7 \%)$ \\
GP / health centre told us child was well & $2(7.7 \%)$ \\
Nobody told us condition was curable & $2(7.7 \%)$ \\
Child was being treated at Hospital & $2(7.7 \%)$ \\
Total & $26(100 \%)$ \\
\hline
\end{tabular}

The number of children in the family $(P=0.548)$, type of family (single $v$ s two parent; $P=0.159$ ), father's education $(P=0.332)$, father's occupation $(P=0.599)$, mother's education $(P=0.802)$, type of cataract: congenital or developmental $(P=0.999)$, uni- or bilateral $(P=0.092)$, time taken to travel to the hospital $(P=0.39)$ or care giver for eye care $(P=0.332)$ were not significantly associated with delay. Although children with both parents had lesser delay as compared with those of single-parent families; and children's whose care giver for eye care were grandmother or other relatives or neighbours and not parents had a greater delay, this was not statistically significant. Only mother's occupation was significantly associated with delay $(P=0.017)$. Children whose mothers were economically independent were more likely to be brought in to the hospital earlier. Qualitative research with 20 respondents revealed that the cost of long-distance travel from rural areas was covered by Department of Health in Durban. The delay was similar in unilateral cataracts as the care takers noticed that something was wrong or different with one eye.

Post-surgery $17 / 69(24.7 \%)$ had visual acuity $>6 / 18$, $20 / 69$ (29.0\%) had vision between $6 / 24$ and 6/60, whereas 32/69 (46.3\%) had visual acuity $<6 / 60$. Eyes with microphthalmos, retinopathy, and congenital glaucoma had visual acuity $<6 / 60$ (poor outcome). The details of association of final best-corrected visual acuity at the third month follow-up are enclosed in Table 3. Using Wilcoxon sign-rank test to compare pre- vs post-operative vision categories, $P<0.001$. There was a substantial improvement in the visual acuity of operated eyes.

The final vision did not depend on gender $(P=0.429)$, preoperative IOP $(P=0.248)$, post-operative IOP $(P=0.468)$, but was associated with age $(P=0.031)$, delay between identification and surgery $(P<0.001)$, type of surgery $(P=0.046)$ and preoperative vision $(P<0.001)$. On multivariate analysis only age was found to be a significant variable (Table 4). By using binary logistic regression with visual outcome at the final follow-up and independent variables like gender, age, preoperative vision, type of cataract, type of surgery, delay for presentation, there was a significant association between age and final vision. The other variables were independent with the visual outcome.

One eye had vitreous wick and needed vitrectomy, whereas another two needed YAG Laser capsulotomy for posterior capsular opacification. One eye had dense visual axis opacification and another had pupillary capture. Only $8(16 \%)$ children were using spectacles at the third month visit. Nine $(18 \%)$ of the children had stereopsis better than or equal to $400 \mathrm{~s}$ of arc. Ten (20\%) children were too young to assess stereopsis.

\section{Discussion}

This may be the first study reporting outcomes of congenital and developmental cataract surgery from the southern part of the African continent. The visual outcome of $17 / 69(24.7 \%) \geq 6 / 18$ was lesser than results from Tanzania $(58 \% \geq 6 / 18),{ }^{15}$ Kenya $(44 \% \geq 6 / 18),{ }^{14}$ Pune, India $(35.8 \% \geq 6 / 18),{ }^{13}$ Miraj, India $(42.2 \% \geq 6 / 18),{ }^{9}$ UK $(40.6 \% \geq 6 / 18),{ }^{8}$ USA $(46.6 \% \geq 6 / 18),{ }^{7}$ China $(30.4 \% \geq 6 / 9){ }^{11}$ Korea $(46.8 \% \geq 6 / 12),{ }^{19}$ Mexico $(40 \% \geq 6 / 18)^{20}$ and Nepal $(36.6 \% \geq 6 / 18) .{ }^{10}$ The relatively poor outcome was because of delay in presentation for surgery and immature visual system with relatively short follow up. The results would get better with longer follow up as visual maturation would occur as refraction, spectacle compliance, and amblyopia treatment are performed properly. Most other studies had older children and longer follow-up, when the visual outcome would improve over time.

On multivariate analysis, only age was found to be a significant variable. Younger age was associated with poor vision perhaps as the visual system was yet to develop. As older children were more likely to have 'delay', paradoxically those with delay had better vision after surgery.

Similarly surgeries in which cataract extraction with PPC and AV were performed (in younger children) had poorer vision as compared with cataract extraction with PPC, AV, and PCIOL (Posterior Chamber Intraocular Lens), which in turn was poorer than only cataract extraction and PCIOL implantation. Also cataract extraction with AV, PPC, and no PCIOL was performed for all microphthalmic eyes. Similarly congenital cataracts had poorer vision than developmental cataracts, but this was not statistically significant. Children with poorer preoperative vision also had poorer post-operative vision as their retina had not been adequately stimulated and were more likely to be deeply amblyopic as found in other studies in Tanzania and India., ${ }^{9} 15$ Both unilateral 
Table 2 Demographic factors associated with delayed presentation for surgery

\begin{tabular}{|c|c|c|c|c|c|c|}
\hline & No delay & $\%$ & Delay & $\%$ & P-value & Total \\
\hline \multicolumn{7}{|l|}{ Family type } \\
\hline Single parent & 7 & 35 & 13 & 65 & \multirow[t]{2}{*}{0.159} & 20 \\
\hline Both parents & 17 & 56.7 & 13 & 43.3 & & 30 \\
\hline \multicolumn{7}{|l|}{ Father's education } \\
\hline Primary & 3 & 60 & 2 & 40 & \multirow{3}{*}{0.332} & 5 \\
\hline Graduate & 4 & 80 & 1 & 20 & & 5 \\
\hline Not applicable & & & & & & 14 \\
\hline \multicolumn{7}{|l|}{ Mother's education } \\
\hline Illiterate & 1 & 100 & 0 & 0 & \multirow{4}{*}{0.802} & 1 \\
\hline Primary & 2 & 33.3 & 4 & 66.7 & & 6 \\
\hline Secondary & 18 & 48.7 & 19 & 51.4 & & 37 \\
\hline Graduate & 2 & 66.7 & 1 & 33.3 & & 3 \\
\hline \multicolumn{7}{|l|}{ Father's occupation } \\
\hline Unemployed & 8 & 53.3 & 7 & 46.7 & \multirow{6}{*}{0.599} & 15 \\
\hline Unskilled & 2 & 33.3 & 4 & 66.7 & & 6 \\
\hline Semiskilled & 7 & 58.3 & 5 & 41.7 & & 12 \\
\hline Skilled & 1 & 50 & 1 & 50 & & 2 \\
\hline Professional & 2 & 100 & 0 & 0 & & 2 \\
\hline Not applicable & & & & & & 13 \\
\hline \multicolumn{7}{|l|}{ Mother's occupation } \\
\hline Unemployed/home-maker & 22 & 56.4 & 17 & 43.6 & \multirow{5}{*}{0.017} & 39 \\
\hline Unskilled & 0 & 0 & 4 & 100 & & 4 \\
\hline Semiskilled & 0 & 0 & 2 & 100 & & 2 \\
\hline Skilled & 0 & 0 & 0 & 0 & & 0 \\
\hline Professional & 1 & 100 & 0 & 0 & & 1 \\
\hline \multicolumn{7}{|l|}{ Caregiver for eyecare ${ }^{\mathrm{a}}$} \\
\hline Mother & 17 & 51.5 & 16 & 48.5 & \multirow{7}{*}{0.332} & 33 \\
\hline Father & 0 & 0 & 1 & 100 & & 1 \\
\hline Both parents & 5 & 55.6 & 4 & 44.4 & & 9 \\
\hline Grandmother & 1 & 25 & 3 & 75 & & 4 \\
\hline Step-mother & 1 & 100 & 0 & 0 & & 1 \\
\hline Aunt & 0 & 0 & 1 & 100 & & 1 \\
\hline Neighbour & 0 & 0 & 1 & 100 & & 1 \\
\hline \multicolumn{7}{|l|}{ Time to travel to hospital } \\
\hline$<30 \min$ & 5 & 50 & 5 & 50 & \multirow{5}{*}{0.39} & 10 \\
\hline $31-60 \mathrm{~min}$ & 7 & 38.9 & 11 & 61.1 & & 18 \\
\hline $61-90 \mathrm{~min}$ & 2 & 40 & 3 & 60 & & 5 \\
\hline $91-120 \mathrm{~min}$ & 5 & 55.6 & 4 & 44.4 & & 9 \\
\hline$>120 \mathrm{~min}$ & 5 & 62.5 & 3 & 37.5 & & 8 \\
\hline \multicolumn{7}{|l|}{ Type of cataract } \\
\hline Congenital & 21 & 48.8 & 22 & 51.2 & \multirow[t]{2}{*}{0.999} & 43 \\
\hline Developmental & 3 & 42.8 & 4 & 57.1 & & 7 \\
\hline \multicolumn{7}{|l|}{ Uni-/bilateral cataract } \\
\hline Unilateral & 5 & 83.3 & 1 & 16.7 & \multirow[t]{2}{*}{0.092} & 6 \\
\hline Bilateral & 19 & 43.2 & 25 & 56.8 & & 44 \\
\hline \multicolumn{7}{|l|}{ Number of children in the family } \\
\hline 1 & 11 & $55 \%$ & 9 & $45 \%$ & & 20 \\
\hline $2-3$ & 10 & $40 \%$ & 15 & $60 \%$ & 0.548 & 25 \\
\hline$>3$ & 3 & $60 \%$ & 2 & $40 \%$ & & 5 \\
\hline Total & 24 & $48 \%$ & 26 & $52 \%$ & & 50 \\
\hline
\end{tabular}

a Person who accompanied the child for $>2$ visits and who signed the consent form for surgery. 
Table 3 Factors affecting visual acuity at the 3 months follow-up

\begin{tabular}{|c|c|c|c|c|c|}
\hline & \multicolumn{2}{|c|}{ Postoperative vision } & \multirow[b]{2}{*}{$\geq 6 / 18$} & \multirow[b]{2}{*}{ Total } & \multirow[b]{2}{*}{ P-value } \\
\hline & $<6 / 60$ & $6 / 60-6 / 18$ & & & \\
\hline \multicolumn{6}{|l|}{ Age } \\
\hline$<6$ months & $4(100 \%)$ & 0 & 0 & 4 & 0.031 \\
\hline 6-12 months & $13(42.9 \%)$ & $2(11.8 \%)$ & $2(11.80 \%)$ & 17 & Fisher's exact test \\
\hline 13-24 months & $3(42.9 \%)$ & $3(42.9 \%)$ & $1(14.3 \%)$ & 7 & \\
\hline 25-60 months & $5(26.3 \%)$ & $8(42.1 \%)$ & $6(31.6 \%)$ & 19 & \\
\hline$>60$ months & $7(31.8 \%)$ & $7(31.8 \%)$ & $8(36.4 \%)$ & 22 & \\
\hline \multicolumn{6}{|l|}{ Gender } \\
\hline Male & $15(40.5 \%)$ & $13(35.1 \%)$ & $9(24.3 \%)$ & 37 & 0.429 \\
\hline Female & $17(53.1 \%)$ & $7(21.9 \%)$ & $8(25 \%)$ & 32 & $\chi^{2}$-test \\
\hline \multicolumn{6}{|l|}{ Preoperative vision } \\
\hline$<6 / 60$ & $31(50.8 \%)$ & $18(29.5 \%)$ & $12(19.7 \%)$ & 61 & $<0.001$ \\
\hline $6 / 60-6 / 18$ & $0(0.00 \%)$ & $1(13.3 \%)$ & $2(66.7 \%)$ & 3 & Wilcoxon sign-rank test \\
\hline$\geq 6 / 18$ & $1(25.0 \%)$ & $1(25.0 \%)$ & $2(50.0 \%)$ & 4 & \\
\hline Missing & & & & 1 & \\
\hline \multicolumn{6}{|l|}{ Preoperative IOP } \\
\hline$<20$ & $21(45.6 \%)$ & $14(30.4 \%)$ & $11(23.7 \%)$ & 46 & 0.999 \\
\hline$>20$ & $1(100 \%)$ & 0 & 0 & 1 & Fisher's exact test \\
\hline Missing & & & & 22 & \\
\hline \multicolumn{6}{|l|}{ Postoperative IOP } \\
\hline$<20$ & $29(49.2 \%)$ & $16(27.1 \%)$ & $14(23.1)$ & 59 & 0.999 \\
\hline$>20$ & $1(100 \%)$ & 0 & 0 & 1 & Fisher's exact test \\
\hline Missing & & & & 9 & \\
\hline No delay & $25(69.4 \%)$ & $4(11.1 \%)$ & $7(19.5 \%)$ & 36 & $<0.001$ \\
\hline Delay & $7(21.2 \%)$ & $16(48.5 \%)$ & $10(30.3 \%)$ & 33 & $\chi^{2}$-test \\
\hline Uveitis & $4(100 \%)$ & 0 & 0 & 4 & 0.143 \\
\hline No uveitis & $28(43.1 \%)$ & $20(30.8 \%)$ & $17(26.1 \%)$ & 65 & \\
\hline Unilateral & $7(46.7 \%)$ & $4(26.7 \%)$ & $4(26.5 \%)$ & 15 & 0.999 \\
\hline Bilateral & $25(46.3 \%)$ & $16(29.6 \%)$ & $13(24.1 \%)$ & 54 & $\chi^{2}$-test \\
\hline \multicolumn{6}{|l|}{ Type of cataract surgery } \\
\hline $\mathrm{Cat}+\mathrm{AV}+\mathrm{PPC}$ & $8(72.7 \%)$ & $2(18.2 \%)$ & $1(9.1 \%)$ & 11 & 0.046 \\
\hline $\mathrm{Cat}+\mathrm{AV}+\mathrm{PPC}+\mathrm{PCIOL}$ & $22(47.8 \%)$ & $15(32.6 \%)$ & $9(19.6 \%)$ & 46 & Fisher's exact test \\
\hline Cat+PCIOL & $1(11.1 \%)$ & $3(33.3 \%)$ & $5(55.6 \%)$ & 9 & \\
\hline Details uncertain & & & & 3 & \\
\hline \multicolumn{6}{|l|}{ Type of cataract } \\
\hline Congenital & $29(48.3 \%)$ & $17(28.3 \%)$ & $14(23.3 \%)$ & 60 & 0.659 \\
\hline Developmental & $3(33.3 \%)$ & $3(33.3 \%)$ & $3(33.3 \%)$ & 9 & Fisher's exact test \\
\hline Total & $32(46.4 \%)$ & $20(29.0 \%)$ & $17(24.6 \%)$ & $69(100 \%)$ & \\
\hline
\end{tabular}

and bilateral cataracts had similar outcomes unlike studies from China. Younger age group and shorter follow-up may be responsible for this lack of difference in the visual outcome gauged against type of cataract. ${ }^{11}$

There was delay in presentation for surgery in this study, like studies from Tanzania, Malawi, India and China. ${ }^{11,20-22}$ The Chinese study had an average delay of 49.6 months (SD 39.8). The average delay for congenital cataracts was 35.7 months (SD 32.2) and no child was operated within 3 months of age and only $15.9 \%$ of children underwent surgery between 3 and 6 years of age. The average delay in our study was 20.7 months, which was similar to a study from Tanzania even though South Africa is a more developed country with a hoary tradition of health-care systems. 'Did not feel the need' or 'the child was seeing fine' were the most common reasons for the delay. Whereas none of the respondents reported that they 'did not have the time' as a cause for delay, many 
Table 4 Multivariate analysis of factors influencing visual outcome

\begin{tabular}{lcccccc}
\hline Variable & Odds ratio & $S E$ & $\mathrm{z}$ & $\mathrm{P}>|\mathrm{z}|$ & $\begin{array}{c}\text { 95\% confidence } \\
\text { interval }\end{array}$ \\
\hline Gender & 1.7 & 0.97 & 0.89 & 0.37 & 0.54 & 5.23 \\
Age & 2.2 & 0.66 & 2.68 & 0.01 & 1.23 & 3.95 \\
Pre-op vision & 1.4 & 0.49 & 1.07 & 0.29 & 0.74 & 2.83 \\
Type of cataract & 2.3 & 2.06 & 0.94 & 0.35 & 0.41 & 13.2 \\
Type of surgery & 0.9 & 0.36 & 0.2 & 0.84 & 0.43 & 2.0 \\
Delay presentation & 2.5 & 1.63 & 1.4 & 0.16 & 0.7 & 8.98 \\
\hline
\end{tabular}

simply felt the child did not need any medical and surgical help as the child was seeing fine. This is in keeping with findings in India where $24.5 \%$ out of 262 respondents felt that their child was seeing well. ${ }^{22}$ In this study, this delay was compounded by the fact that many care givers were not advised appropriately by general practitioners or other health-care practitioners and hence continued to believe their child did not need any further assistance. Cost of travelling to the hospital for surgery was a barrier. Interviews with 20 respondents revealed that the cost of their long-distance travel from rural areas was covered by the Department of Health. People who lived closer to the hospital struggled more with the cost of public transportation. This was similar to results from India ${ }^{22}$ and Tanzania. ${ }^{18}$ A study from Mexico had cost and distances as major barriers to uptake of pediatric cataract. ${ }^{20}$ The barriers for early presentation for surgery were awareness and health-care system related issuesboth of which are eminently amenable by more health promotion and education of communities, general doctors and paramedics. The health-care providers could be taught the red reflex test as was done in New Zealand to screen leucocoria. ${ }^{23}$ The direct cost of surgery was not a significant barrier as the surgery offered at Inkosi Albert Luthuli Central Hospital (the hospital in this study) was provided for free. Surprisingly, the delay was similar for unilateral and bilateral cataracts. It would have been assumed that bilateral cataracts would have lesser delay in presentation due to more profound visual impairment but perhaps the care takers noticed that something was wrong or different with one eye in unilateral cataracts and brought them to the notice of health-care providers.

The surgeries were performed as per international norms. Only one child needed a second extra intervention (vitrectomy for a vitreous wick syndrome). The visual rehabilitation of these children was still not complete and visual acuity result $\mathrm{s}$ may be better if measured after one or two years like a study from UK, USA, or India. ${ }^{7-9}$ Visual maturation would have occurred and refraction, spectacles wear, and amblyopia treatment would have improved vision. A poor follow-up and amblyopia treatment would condemn these children to sub-optimal vision. A survey of schools for the blind in four east African countries found nearly $20 \%$ of students inmates to be blind either by unoperated cataract or had cataract surgery, but no visual rehabilitation. ${ }^{24}$ Factors that prolonged the time between identification and surgery would also impede regular and complete follow-up as was seen in Tanzania and India. ${ }^{22,25}$ The low percentage of children using spectacles after surgery was dismaying. Active interventions are needed to ensure provision and compliance of spectacles and monitor amblyopia treatment.

Other than a study from Tanzania, 15 this may be the only study from Africa documenting pediatric cataract surgery results in infants, toddlers, and preschool children. Further follow-up and analysis is needed to report on longer term prognosis and visual outcomes.

\section{Summary}

What was known before

- There is a delay between identification and survey of children with congenital cataracts in developing countries.

- Visual outcomes of congenital cataract surgery are suboptimal as compared with adult cataracts.

- Poorer preoperative vision is associated with poorer postoperative vision.

What this study adds

- There is a delay between identification and actual surgery of congenital cataracts even in South Africa, which has the best health-care system on the African continent.

- Economically independent mother's children are less likely to have a delay between recognition and surgery.

- Very young children have poorer visual outcomes after congenital cataract surgery, in spite of lesser delay and standardized techniques. But their vision would improve over time.

\section{Conflict of interest}

The authors declare no conflict of interest.

\section{Acknowledgements}

We thank Jill Sloan, Nafisa Baboo, Hendrik Grobbelaar, Musa Gumede and Mbali Mpungose from Orbis Africa for help in logistics and data collection. Shrivallabh Sane of Data Clinic, Pune and Bharti Vidyapeeth Medical College, Pune for statistical analysis. We also thank Jyoti Jaggernath, African Vision Research Institute for her inputs. The study was funded by the Pediatric Cataract Initiative, Bausch and Lomb and Lions International. 


\section{References}

1 Gilbert C, Foster A. Childhood blindness in the context of VISION 2020-the right to sight. Bull World Health Organ 2001; 79(3): 227-232.

2 Rahi JS, Gilbert CE, Foster A, Minassian DC. Measuring the burden of childhood blindness. Br J Ophthalmol 1999; 83: 387-388.

3 Gogate P, Muhit M. Childhood blindness and cataract in developing countries. Community Eye Health 2009; 22(69): $4-5$.

4 Gilbert CE, Rahi JS, Quinn GE. Visual impairment and blindness in children. In: Johnson GJ, Weale R, Minassian DC, West SK (eds). The Epidemiology of Eye Disease, 2nd edn. Arnold: London, UK, 2003.

5 Ram J, Brar GS, Kaushik S, Gupta A, Gupta A. Role of posterior capsulotomy with vitrectomy and intraocular lens design and material in reducing posterior capsule opacification after pediatric cataract surgery. J Cataract Refract Surg 2003; 29: 1579-1584.

6 Wilson ME, Trivedi RH, Bartholomew LR, Pershing S. Comparison of anterior vitrectorhexis and continuous curvilinear capsulorhexis in pediatric cataract and intraocular lens implantation surgery: a 10-year analysis. J AAPOS 2007; 11(5): 443-447.

7 Ledoux DM, Trivedi RH, Wilson ME, Payne JF. Pediatric cataract extraction with IOL: visual acuity outcome when measured at age 4years and older. J AAPOS 2007; 11: 218-224.

8 Chak M, Wade A, Rahi JS. British Congenital Cataract Interest Group. Long-term visual acuity and its predictors after surgery for congenital cataract: findings of the British congenital cataract study. Invest Ophthalmol Vis Sci 2006; 47(10): 4262-4269.

9 Gogate PM, Sahasrabudhe M, Shah M, Patil S, Kulkarni AN, Trivedi $\mathrm{R}$ et al. Long term outcomes of bilateral congenital and developmental cataracts operated in Maharashtra, India. Indian J Ophthalmol 2014; 62(2): 186-195.

10 Thakur J, Reddy H, Wilson Jr ME, Paudyal G, Gurung R, Thapa $\mathrm{S}$ et al. Pediatric cataract surgery in Nepal. J Cataract Refract Surg 2004; 30: 1629-1635.

11 You C, Wu X, Zhang Y, Dai Y, Huang Y, Xie L. Visual impairment and delay in presentation for surgery in chinese pediatric patients with cataract. Ophthalmology 2011; 118(1): 17-23.

12 Bhusal S, Ram J, Sukhija J, Pandey S, Kaushik SS. Comparison of the outcome of implantation of hydrophobic acrylic versus silicone intraocular lenses in pediatric cataract: prospective randomized study. Can J Ophthalmol 2010; 45(5): 531-536.
13 Gogate P, Khandekar R, Srisimal M, Dole K, Taras S, Kulkarni $\mathrm{S}$ et al. Delayed presentation of cataracts in children: are they worth operating upon? Ophthalmic Epidemiol 2010; 17(1): 25-33.

14 Yorston D, Wood M, Foster A. Results of cataract surgery in young children in east Africa. Br J Ophthalmol 2001; 85(3): 267-271.

15 Bowman R, Karibu J, Negretti G, Wood M. Outcome of bilateral cataract surgery in Tanzanian children. Ophthalmology 2007; 114(12): 2287-2292.

16 Msukwa G, Ninguna M, Tumweisgye C, Shilo B, Courtright $P$, Lewallen S. Cataracts in children attending schools for the blind and resource centers in Eastern Africa. Ophthalmology 2009; 116: 1009-1012.

17 Dahan E, Drusedau MU. Choice of lens and dioptric power in pediatric pseudophakia. J Cataract Refract Surg 1997; 23: 618-623.

18 Mwende J, Bronsard A, Mosha M, Bowman R, Geneau R, Courtright P. Delay in presentation to hospital for surgery for congenital and developmental cataract in Tanzania. Br J Ophthalmol 2005; 89: 1478-1482.

19 Park JH, Yu YS, Kim JH, Kim SJ, Choung HK. Visual function after primary posterior chamber intraocular lens implantation in pediatric unilateral cataract: stereopsis and visual acuity. Korean J Ophthalmol 2007; 21(4): 195-200.

20 Congdon NG, Ruiz S, Suzuki M, Herrera V. Determinants of pediatric cataract program outcomes and follow up in a large series in Mexico. J Cataract Refract Surg 2007; 33: 1775-1780.

21 Schulze Schwering M, Finger RP, Barrows J, Nyrenda M, Kalua K. Barriers to uptake of free pediatric cataract surgery in Malawi. Ophthalmic Epidemiol 2014; 21(3): 138-143.

22 Gogate P, Patil S, Kulkarni A, Mahadik A, Tamboli R, Mane $\mathrm{R}$ et al. Barriers to follow-up for pediatric cataract surgery in Maharashtra, India. How regular follow-up is important for good outcome. Indian J Ophthalmol 2014; 62(3): 327-332.

23 Pon JA, Bevin TH, Herbison P, Taylor BJ, Sanderson G. A novel instrument for assessing the retinal red reflex for non-ophthalmic health professionals. Clin Exp Optom 2005; 88(3): 160-164.

24 Msukwa G, Njuguna M, Tumwesigye C, Shilio B, Courtright $\mathrm{P}$, Lewallen $\mathrm{S}$. Cataract in children attending schools for the blind and resource centers in eastern Africa. Ophthalmology 2009; 116(5): 1009-1012.

25 Kishiki E, Shirima S, Lewallen S, Courtright P. Improving postoperative follow-up of children receiving surgery for congenital or developmental cataracts in Africa. J AAPOS 2009; 13(3): 280-282. 